\title{
COMPORTAMENTO REOLÓGICO DE EXTRATOS DE GRÃOS, FARINHA INTEGRAL E ISOLADO PROTÉICO DE SOJA *
}

\author{
ROSANE DA SILVA RODRIGUES ** \\ ÂNGELA MARIA GOZZO * \\ ROBERTO HERMÍNIO MORETTI ****
}

\begin{abstract}
Estudou-se o comportamento reológico de extratos elaborados com grãos, farinha integral e isolado protéico de soja. Extratos com 3\% de proteína foram obtidos de grãos de soja (em equipamento conhecido como "vaca mecânica"), de farinha integral e de isolado protéico (por dissolução em água) e pasteurizados a $74 \pm 2^{\circ} \mathrm{C}$ por 15 seg. Os parâmetros reológicos estudados foram o coeficiente de consistência, o índice de comportamento do fluxo e a viscosidade aparente. Foram determinados, também, sólidos totais, proteínas, lipídios, cinzas, fibra bruta, carboidratos e índice de sedimentação (AOAC, 1995). Verificou-se que a viscosidade aparente, a 4 e $25^{\circ} \mathrm{C}$, do extrato obtido de grãos de soja (fluido nãonewtoniano com comportamento pseudoplástico) foi maior que a do extrato da farinha (fluido não-newtoniano com comportamento pseudoplástico a $4^{\circ} \mathrm{C}$ e dilatante a $25^{\circ} \mathrm{C}$ ) e do isolado (fluido newtoniano). O maior índice de sedimentação constatado no extrato de farinha integral e o baixo teor de sólidos solúveis no isolado protéico foram determinantes, entre outros fatores, no comportamento reológico verificado.
\end{abstract}

PALAVRAS-CHAVE: SOJA-PROPRIEDADES REOLÓGICAS; EXTRATO DE SOJA.

\section{INTRODUÇÃO}

A soja apresenta reconhecido valor nutricional. Vem sendo estudada como alimento funcional pelas descobertas científicas de que pode

* Parte da tese de doutorado do primeiro autor.

** Doutora, Professora, Departamento de Ciência dos Alimentos, Universidade Federal de Pelotas (UFPel), Pelotas, RS

(e-mail:rosane.rodrigues @ufpel.tche.br).

*** MSc., Doutoranda em Engenharia de Alimentos, Faculdade de Engenharia de Alimentos (FEA), Universidade de Campinas (UNICAMP), Campinas, SP

(e-mail: angelamg@fea.uniamp.br).

**** Doutor, Professor, Departamento de Tecnologia de Alimentos, FEA, UNICAMP, Campinas, SP (e-mail: moretti@fea.unicamp.br). 
prevenir enfermidades como alguns tipos de câncer, doenças cardiovasculares e sintomas da pós-menopausa (MESSINA, 1999).

O Brasil destaca-se como segundo produtor e maior exportador mundial de soja. Entretanto, o consumo dessa leguminosa, de seus subprodutos e derivados ainda é restrito no país. Isto se deve à influência de aspectos socioculturais nos hábitos alimentares, principais fatores limitantes à sua aceitação e ao consumo cotidiano (PANORAMA BRASIL, 2003).

Os grãos de soja vêm sendo utilizados sobretudo para a extração de óleo vegetal, sendo a torta ou farelo resultantes empregados majoritariamente como matérias-primas para ração animal (FREITAS et al., 2000). Os produtos protéicos de soja na forma de farinha, isolado e concentrado têm sido utilizados basicamente como melhoradores tecnológicos de alimentos industrializados (MORAIS e SILVA, 1996).

O extrato de soja, também conhecido como "leite de soja", constitui um dos produtos mais difundidos dessa leguminosa. Inicialmente, sua utilização esteve limitada a pessoas com intolerância à lactose, vegetarianos e indivíduos com restrições alimentares ou de ordem religiosa. Posteriormente, os extratos comerciais de soja alcançaram penetração considerável no mercado como fonte protéica barata (em substituição ao leite bovino) para atender populações carentes (LIU, 1999; BERK, 1992). O consumo vem aumentando, visivelmente, impulsionado pelo novo enfoque da soja relacionado com a prevenção de algumas doenças. Além disso, a soja apresenta versatilidade para utilização na forma direta ou na elaboração de outros produtos como sorvetes, análogos de leite condensado, bebidas e em mistura com inúmeras outras matérias-primas (PRUDÊNCIO et al., 2002; DELLA MODESTA et al., 2001; INUI et al., 2001; OMUETI et al., 2000; OTERO et al., 1998; PAZ FRASSINO et al., 1998; SILVA et al. 1998).

Os extratos de soja são elaborados, normalmente, a partir de grãos inteiros, cujo processo consiste basicamente na seleção e lavagem dos grãos, maceração em água, retirada da casca, desintegração, aquecimento e separação do resíduo (LIU, 1999; BERK, 1992; FERREIRA et al., 1974). O extrato também pode ser obtido da farinha ou do isolado protéico de soja (o que permite eliminar algumas etapas 
do processo), mas com alterações na sua composição química, sensorial, nutricional e nas propriedades reológicas.

O conhecimento das propriedades reológicas dos alimentos é fundamental no dimensionamento e operacionalização de equipamentos envolvidos no seu processamento, bem como no controle de qualidade e na determinação da sua vida-de-prateleira. Muitos dos atributos sensoriais associados à textura de emulsões alimentícias estão diretamente relacionados com propriedades como a viscosidade (BUFFO e REINECCIUS, 2002; MULLER, 1973), parâmetro intimamente ligado com a aceitabilidade do produto pelos consumidores (YANES et al., 2002; PENNA et al., 2001; COURREGELONGUE et al., 1999; SILVA et al., 1998).

O objetivo deste trabalho foi verificar o comportamento reológico de extratos elaborados com grãos, farinha integral e isolado protéico de soja.

\section{MATERIAL E MÉTODOS}

\subsection{MATÉRIAS-PRIMAS UTILIZADAS}

Foram utilizados grãos de soja [Glycine max (L.) Merril], da variedade Embrapa 48 (safra 2001), produzidos pela empresa Sementes Brejeiro S.A. (Orlândia - SP), farinha de soja integral fornecida pela Perdigão S.A. e isolado protéico de soja HO159 $®$ da Protein Technologies International.

\subsection{OBTENÇÃO DO EXTRATO DE SOJA}

O extrato proveniente dos grãos foi obtido em equipamento conhecido como "vaca mecânica", de propriedade da Prefeitura de Nova Odessa (SP). Após descascamento em descascador de rolos e maceração em água por 2 horas em temperatura ambiente, os grãos foram submetidos à trituração a quente, separação do resíduo e cozimento. Os extratos provenientes da farinha e do isolado protéico foram obtidos pela dissolução da respectiva matéria-prima em água. Em todos os casos, a proporção de matéria-prima:água foi calculada visando obter extratos com 3\% de proteína. 
Os extratos de soja foram desodorizados em equipamento piloto desenvolvido no Instituto de Tecnologia de Alimentos (ITAL) de Campinas (SP). Esse, consiste basicamente em coluna recheada com anéis de vidro em que o líquido passa em contracorrente ao vapor de água superaquecido (MORAES, 2002). Na seqüência, foram pasteurizados a temperatura de $74 \pm 2^{\circ} \mathrm{C}$ por 15 segundos, acondicionados em garrafas de polietileno tereftalato (PET) com capacidade para $250 \mathrm{~mL}$, resfriados a $3-4^{\circ} \mathrm{C}$, e mantidos sob refrigeração $\left(4^{\circ} \mathrm{C}\right)$ até o momento das análises.

\subsection{COMPOSIÇÃO QUÍMICA DOS EXTRATOS}

Nos extratos obtidos de grãos, da farinha integral e do isolado protéico de soja foram determinados, em sextuplicata, sólidos totais, proteínas, lipídios, cinzas, fibra bruta e índice de sedimentação, conforme metodologias descritas na AOAC (1995). Os carboidratos foram calculados por diferença (carboidratos $=100$ - umidade - proteínas lipídios - cinzas - fibras).

\subsection{PROPRIEDADES REOLÓGICAS DOS EXTRATOS DE SOJA}

As medidas reológicas foram efetuadas em reômetro rotacional Brookfield, modelo RVIII (Brookfield Engineering Laboratories), acoplado a banho termostático com temperatura controlada. O coeficiente de consistência e o índice de comportamento do fluxo foram determinados a $4^{\circ} \mathrm{C} \mathrm{e} 25^{\circ} \mathrm{C}$ na velocidade de $12,5 \mathrm{rpm}$ até $250 \mathrm{rpm}$, com intervalo de espera de 15 segundos entre cada aumento, num total de 5 minutos para o tempo de rampa crescente. Determinou-se também a viscosidade aparente dos extratos nas temperaturas de 4 e $25^{\circ} \mathrm{C}$, com taxa de deformação constante de $100 \mathrm{~s}^{-1}$. Para a captura dos dados utilizou-se o programa computacional Rheocalc 2.3 (Brookfield Engineering Laboratories).

\subsection{ANÁLISE ESTATÍSTICA}

Os resultados das determinações químicas foram compilados e analisados pelo programa Statistica, versão 5.0 (STATISTICA, 1995). 
Utilizou-se a análise de variância (ANOVA), o teste $F$ e para a comparação das médias dos resultados das amostras o teste de Tukey $(p \leq 0,05)$. Os parâmetros reológicos foram analisados por métodos estatísticos quantitativos com determinação das equações de regressão correspondentes.

\section{RESULTADOS E DISCUSSÃO}

A Tabela 1 apresenta os resultados das determinações físico-químicas realizadas nos extratos de soja elaborados a partir dos grãos, da farinha integral e do isolado protéico.

Observou-se que os extratos, de forma geral, apresentaram diferenças significativas $(p \leq 0,05)$ entre si quanto à composição físico-química analisada, devido à composição química da matéria-prima inicial e aos processamentos que os originaram.

\section{TABELA 1 - COMPOSIÇÃO FÍSICO-QUÍMICA DOS EXTRATOS OBTIDOS DOS GRÃOS, DA FARINHA INTEGRAL E DO ISOLADO PROTÉICO DE SOJA}

\begin{tabular}{lccc}
\hline \multicolumn{1}{c}{ Determina ${ }^{\mathrm{a}} \mathbf{0}$} & $\begin{array}{c}\text { Extrato de } \\
\text { gra os de soja }\end{array}$ & $\begin{array}{c}\text { Extrato de } \\
\text { farinha integral } \\
\text { de soja }\end{array}$ & $\begin{array}{c}\text { Extrato de } \\
\text { isolado protøico } \\
\text { de soja }\end{array}$ \\
\hline S lidos totais (\%) & $5,88 \pm 0,01^{\mathrm{a}}$ & $6,68 \pm 0,57^{\mathrm{b}}$ & $3,65 \pm 0,00^{\mathrm{c}}$ \\
Prote nas (\%) & $3,03 \pm 0,02^{\mathrm{a}}$ & $3,03 \pm 0,01^{\mathrm{ab}}$ & $3,00 \pm 0,03^{\mathrm{b}}$ \\
Lip dios (\%) & $0,89 \pm 0,02^{\mathrm{a}}$ & $1,47 \pm 0,02^{\mathrm{b}}$ & $0,02 \pm 0,00^{\mathrm{c}}$ \\
Cinzas (\%) & $0,23 \pm 0,01^{\mathrm{a}}$ & $0,34 \pm 0,01^{\mathrm{b}}$ & $0,42 \pm 0,01^{\mathrm{c}}$ \\
Fibra bruta (\%) & $0,07 \pm 0,00^{\mathrm{a}}$ & $0,28 \pm 0,10^{\mathrm{b}}$ & $0,02 \pm 0,01^{\mathrm{a}}$ \\
Carboidratos (\%) & 1,66 & 1,56 & 0,19 \\
"ndice de & $13,50 \pm 0,35^{\mathrm{a}}$ & $25,05 \pm 9,22^{\mathrm{b}}$ & $2,70 \pm 5,61^{\mathrm{c}}$ \\
sedimenta a & & & \\
\hline
\end{tabular}

* Calculado por diferença (carboidratos = 100 - umidade - proteínas - lipídios cinzas - fibra bruta, sendo umidade $=100$ - sólidos totais).

Os valores correspondem à média de 6 repetições \pm estimativa de desvio-padrão. Médias na mesma linha seguidas por letras distintas diferem significativamente entre si pelo teste de Tukey ( $p \leq 0,05)$.

A estabilidade dos extratos, verificada pelo índice de sedimentação pode diferenciá-los em relação à matéria-prima de origem. De acordo com a Tabela 1, o extrato obtido do isolado mostrou maior estabilidade. 
O teor relativo de sólidos totais na composição dos mesmos pode ter contribuído para o resultado observado. A intensidade do tratamento térmico, usado na inativação enzimática da farinha, pode ter influenciado a solubilidade das proteínas pela desnaturação irreversível das mesmas. De acordo com RUSTOM et al. (1996), as proteínas desnaturadas insolúveis tendem a formar agregados que sedimentam-se rapidamente, os quais estão associados à textura indesejável em bebidas por conferirem sensação de arenosidade à boca. Essas partículas podem, da mesma forma, afetar negativamente parâmetros reológicos do produto, como a viscosidade.

Os parâmetros reológicos dos extratos obtidos de grãos, da farinha integral e do isolado protéico de soja são mostrados na Tabela 2 e representados na Figura 1.

\section{TABELA 2 - PARÂMETROS REOLÓGICOS DOS EXTRATOS OBTIDOS DOS GRÃOS, DA FARINHA INTEGRAL E DO ISOLADO PROTÉICO DE SOJA, A 4 E 25ㄷ, SEGUNDO O MODELO DA "LEI DE POTÊNCIA"}

\begin{tabular}{|c|c|c|c|c|c|c|}
\hline \multirow[t]{2}{*}{ Extrato } & \multicolumn{2}{|c|}{$\begin{array}{l}\text { Coeficiente de } \\
\text { consistChcia (K) }\end{array}$} & \multicolumn{2}{|c|}{$\begin{array}{l}\text { "ndice de } \\
\text { comportamento } \\
\text { do fluxo (n) }\end{array}$} & \multicolumn{2}{|c|}{$\begin{array}{l}\text { Coeficiente de } \\
\text { correla a o }\left(R^{2}\right)\end{array}$} \\
\hline & $4 \mathrm{C}$ & $25 \mathrm{C}$ & $4 C$ & $25 \mathrm{C}$ & $4 \mathrm{C}$ & $25 \mathrm{C}$ \\
\hline $\begin{array}{l}\text { Gra os de soja } \\
\text { Farinha integral de soja } \\
\text { Isolado protØico de soja }\end{array}$ & $\begin{array}{l}2,72 \\
0,93 \\
0,31\end{array}$ & $\begin{array}{l}2,08 \\
0,20 \\
0,11\end{array}$ & $\begin{array}{c}0,74 \\
0,94 \\
1,0\end{array}$ & $\begin{array}{c}0,69 \\
1,20 \\
1,0\end{array}$ & $\begin{array}{l}0,97 \\
0,92 \\
0,93\end{array}$ & $\begin{array}{l}0,89 \\
0,82 \\
0,85\end{array}$ \\
\hline
\end{tabular}

O extrato elaborado com grãos de soja (Tabela 2 e Figura 1) mostrouse como fluido não-newtoniano e comportamento pseudoplástico $(n<1)$, concordando com o observado por WANG et al. (2001) e TRINDADE et al. (1997). Já o extrato obtido do isolado protéico de soja apresentouse como fluido newtoniano $(n=1)$.

O índice de comportamento do fluxo (n) não mudou consideravelmente quando a temperatura passou de 4 para $25^{\circ} \mathrm{C}$ (Tabela 2), indicando que a temperatura não influencia o grau de comportamento nãonewtoniano exibido pelo extrato elaborado com grãos de soja. Por outro lado, o extrato elaborado com farinha integral de soja apresentou comportamento ligeiramente pseudoplástico $(n<1)$ a $4^{\circ} \mathrm{C}$, passando a dilatante $(n>1)$ quando a temperatura aumentou para $25^{\circ} \mathrm{C}$. 
FIGURA 1 - RELAÇÃO ENTRE TENSÃO DE CISALHAMENTO E TAXA DE DEFORMAÇÃO (a) E RELAÇÃO ENTRE VISCOSIDADE APARENTE E TAXA DE DEFORMAÇÃO (b) DOS EXTRATOS OBTIDOS DE GRÃOS, FARINHA INTEGRAL E ISOLADO PROTÉICO DE SOJA, A 4 E $25^{\circ} \mathrm{C}$

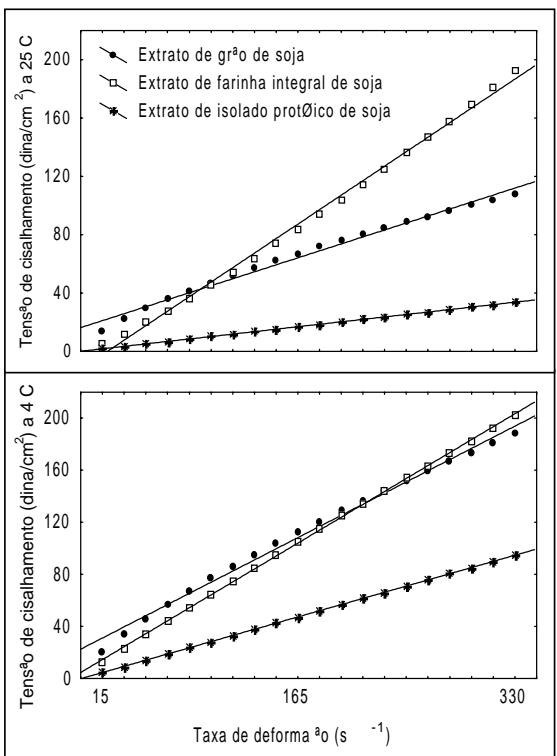

(a)

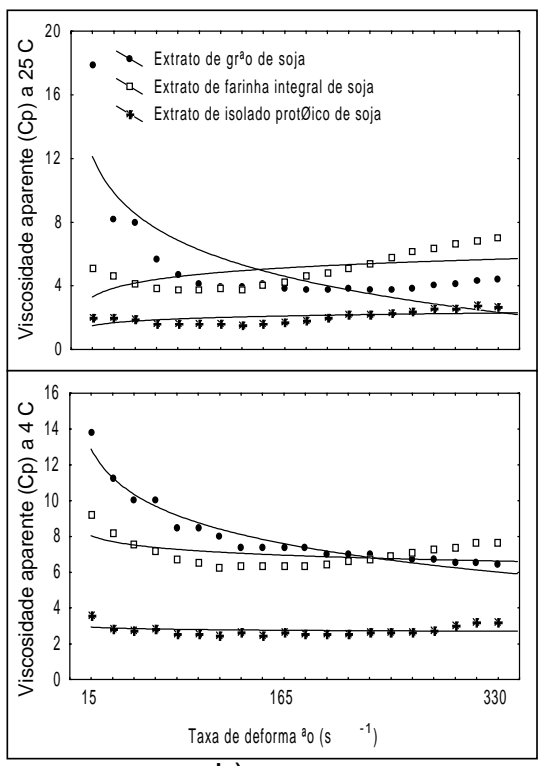

b)

Em taxas de deformação mais elevadas $\left(>150 \mathrm{~s}^{-1}\right)$, a viscosidade aparente do extrato obtido de grãos de soja foi menor do que a do extrato obtido da farinha integral (Figura $1 \mathrm{~b}$ ). A relação inversa entre viscosidade e taxa de deformação em fluidos pseudoplásticos devese ao maior alinhamento das moléculas em direção ao fluxo formado, induzindo maior fluidez do líquido e menor atrito. Os fluidos dilatantes, por sua vez, geralmente, contêm altas concentrações de sólidos em suspensão. Na medida em que a taxa de deformação aumenta, os aglomerados de partículas sólidas formadas não são suficientemente lubrificados pela fase líquida e os mesmos permanecem juntos, aumentando a tensão (NSOFOR e OSUJI, 1997). 
O comportamento reológico observado no extrato obtido da farinha integral de soja está relacionado com a provável aglomeração das partículas de proteína desnaturadas, causando maior índice de sedimentação comparativamente aos demais extratos (Tabela 1).

A viscosidade aparente dos extratos de soja é mostrada na Figura 2.

\section{FIGURA 2 - VISCOSIDADE APARENTE DOS EXTRATOS OBTIDOS DE GRÃOS, FARINHA INTEGRAL E ISOLADO PROTÉICO DE SOJA, EM TEMPERATURAS DE 4 E $25^{\circ} \mathrm{C}$ E TAXA DE DEFORMAÇÃO DE 100S $^{-1}$}

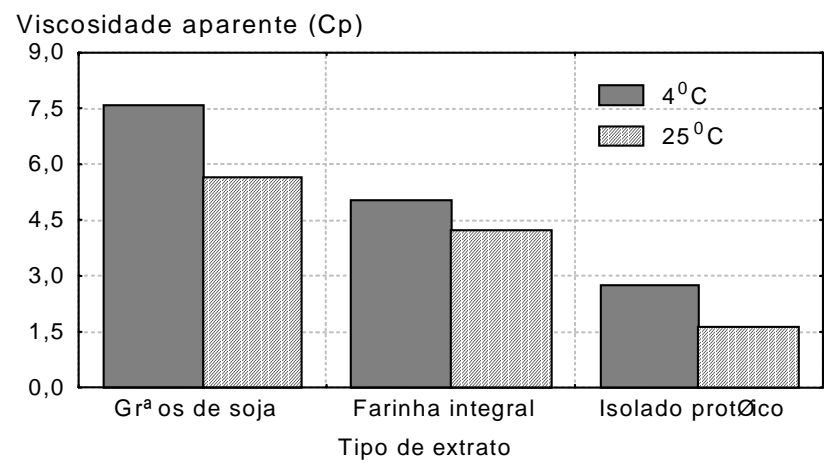

A viscosidade aparente do extrato obtido dos grãos de soja foi maior que a da farinha e do isolado, em ambas as temperaturas estudadas (Figura 2). De acordo com OGUNTUNDE e AKINTOYE (1991), a viscosidade depende do teor de sólidos totais e da composição de proteínas, de lipídios e de fibras. Era provável que a viscosidade fosse maior para o extrato obtido da farinha integral de soja pelo maior teor de lipídios e fibras (Tabela 1). Tal fato não foi observado, possivelmente devido à rápida sedimentação dessas partículas durante o tempo de espera (30 segundos) para a realização da leitura da amostra no viscosímetro.

Muitos são os fatores que podem afetar o comportamento reológico de determinado fluido. Para extratos de soja tem sido encontrada na literatura variação de viscosidade entre 3,8 e 14,7 Cp. Tal 
comportamento tem sido atribuído a diferenças nos processos de obtenção dos extratos e/ou à variedade de soja utilizada (WANG et al., 2001; SAXENA e SINGH, 1997; REDDY e MITAL, 1992). A viscosidade das soluções dependem da concentração, tamanho e forma das moléculas em suspensão, das conformações que as mesmas adotam no solvente, das oscilações entre as ligações formadas e do número de colisões intra e intermoleculares (BUFFO e REINECCIUS, 2002). NSOFOR e OSUJI (1997) propõem que a viscosidade dos extratos de soja tratados termicamente possa ser afetada pelo número de ligações cruzadas resultantes da associação entre polissacarídios e proteínas solúveis e insolúveis, parcialmente desnaturadas.

A temperatura afetou a viscosidade (Figura 2), ou seja, maiores temperaturas resultaram em viscosidades aparentes menores para todos os extratos, concordando com os relato de KAYA e BELIBAGH (2002), KIM et al. (1984) e FORSTER e FERRIER (1979).

\section{CONCLUSÃO}

O extrato elaborado com grãos de soja mostrou-se como fluido nãonewtoniano, com comportamento pseudoplástico, e o extrato obtido de farinha integral de soja como fluido não-newtoniano com comportamento pseudoplástico a $4^{\circ} \mathrm{C}$ e dilatante a $25^{\circ} \mathrm{C}$. Já o elaborado com isolado protéico de soja apresentou-se como fluido newtoniano.

A viscosidade aparente, nas temperaturas de 4 e $25^{\circ} \mathrm{C}$, do extrato obtido de grãos de soja foi maior que a da farinha e do isolado.

O maior índice de sedimentação verificado no extrato de farinha integral e o baixo teor de sólidos totais no isolado protéico foram determinantes, entre outros fatores, no comportamento reológico verificado.

\section{Abstract}

RHEOLOGICAL BEHAVIOR OF SOYMILK, WHOLE SOY FLOUR AND SOY ISOLATED PROTEIN

The rheological properties of extracts elaborated with soybeans, whole soy flour and isolated protein were studied. Extracts with $3 \%$ of protein were obtained from soybeans (in a equipment called "mechanic cow"), whole soy flour and isolated soy 
protein (by dissolution in water) and pasteurized at $74 \pm 2^{\circ} \mathrm{C}$ for $15 \mathrm{seg}$. The rheological parameters studied were the flow behavior index, consistency coefficient and apparent viscosity. Total solid, proteins, lipids, ashes, brute fiber, carbohydrates and sedimentation index (AOAC, 1995) was also determined. The apparent viscosity, at 4 and $25^{\circ} \mathrm{C}$, of the extract obtained from soybeans (non-newtonian fluid with pseudoplastic behavior), was greater than the one of whole soy flour extract (nonnewtonian fluid with pseudoplastic behavior at $4^{\circ} \mathrm{C}$ and dilatant at $25^{\circ} \mathrm{C}$ ) and of the isolated soy protein extract (Newtonian fluid). The highest sedimentation index verified in the whole soy flour extract and the low content of soluble solids in the extract of isolated soy protein defined, among others factors, the rheological behavior verified.

KEY-WORDS: SOY-RHEOLOGICAL PROPERTIES; SOY EXTRACT.

\section{REFERÊNCIAS}

1 AOAC. Association of Official Analitycal Chemists. Official methods of analysis of the AOAC. $12^{\text {th }}$ ed. Washington, 1995.

2 BERK, Z. Technology of production of edible flours and protein products from soybeans. Roma, 1992. (FAO Agricultural Services Bulletin, n. 97).

3 BUFFO, R. A.; REINECCIUS, G. A. Modeling the rheology of concentrated beverage emulsions. Journal of Food Engineering, v. 51, p. 267-272, 2002.

4 COURREGELONGUE, S.; SCHLICH, P.; NOBLE, A. C. Using repeated ingestion to determine the effect of sweetness, viscosity and oilness on temporal perception of soymilk adstringency. Food Quality and Preference, v. 10, p. 273-279, 1999.

5 DELLA MODESTA, R. C.; FELBERG, I.; CABRAL, L. C.; FERREIRA, J. C. S. Avaliação da influência da adição de "leite" de castanha-do-brasil na cor de "leites" de soja integral e hidrossolúvel. In: SIMPÓSIO LATINO AMERICANO DE CIÊNCIA DOS ALIMENTOS, 4., 2001, Campinas. Anais... Campinas: UNICAMP, 2001. 1 CD-ROM.

6 FERREIRA, E.; BORGES, J. M.; MENDES, A. C. C. Novo processo de elaboração de leite de soja. Revista Ceres, v. 21, n.117, p.422-425, 1974.

7 FORSTER, L. L.; FERRIER, L. K. Viscometric characteristics of whole soybean milk. Journal of Food Science, v. 44, n. 2, p. 583-590, 1979.

8 FREITAS, S. M. de; BARBOSA, M. Z.; FRANCA, T. J. F. Cadeia de produção de soja no Brasil: o caso do óleo. Informações Econômicas, v. 30, n. 12, p. 30-40, dez., 2000.

9 INUI, K. H.; NAKAZAKI, C. D; PRADO, C. C. A.; TSUHAKO, V. P.; ADELL, E. A. A.; LIMA U. A. Alimento concentrado e adoçado à base de extrato hidrossolúvel de soja. In: SIMPÓSIO LATINO-AMERICANO DE CIÊNCIA DOS ALIMENTOS, 4., 2001, Campinas. Anais... Campinas: UNICAMP, nov., 2001. 1 CD-ROM. 
KAYA, A.; BELIBAGH, K. B. Rheology of solid gaziantep pekmez. Journal of Food Engineering, v. 54, p. 221-226, 2002.

11 KIM, W. J.; KIM, N. M.; KIM, D. H. Some factors affecting the viscometric characteristics of soy milk. Korean Journal of Food Science and Technology, v. 16, n. 4, p. 423-428, 1984.

12 LIU, K. Soybeans: chemistry, technology and utilization. New York: Chapman \& Hall, 1999. 532 p.

13 MESSINA, M. J. Legumes and soybeans:overview of their nutritional profiles and health effects. American Journal of Clinical Nutrition, v. 70 (suppl.), p. 439-450, 1999.

14 MORAES, R. M. de Montagem e avaliação de um equipamento para desodorização de "leite de soja" por arraste de vapor superaquecido. Campinas, 2002. 51 p. Tese (Doutorado) - Faculdade de Engenharia de Alimentos, Universidade Estadual de Campinas.

15 MORAIS, A. A. C.; SILVA, A. L. Soja: suas aplicações. Rio de Janeiro: Editora Médica e Científica, 1996. $259 \mathrm{p}$.

16 MULLER, H. G. Introducción a la reologia de los alimentos. Zaragoza: Acribia, 1973. 174 p.

17 NSOFOR, L. M.; OSUJI, C. M. Stability, rheology and chemical properties of soymilk concentrates developed from sprouted soybeans. Journal of Food Science and Technology, v. 34, n. 1, p. 33-40, 1997.

OGUNTUNDE, A. O.; AKINTOYE, O. A. Measurement and comparison of density, specific heat and viscosity of cow's milk and soymilk. Journal of Food Engineering, v. 13, n. 3, p. 221-230, 1991.

19 OMUETI, O.; OGUNTONA, E. B.; FAIYEOLA, O.; ASHAYE, O. A. Nutritional evaluation of home-prepared soy-corn milk: a protein beverage. Nutrition and Food Science, v. 30, n. 3, p. 128-132, 2000.

20 OTERO, M.; RODRIGUEZ, T.; CAMEJO, J.; HOMBRE, R. de; VALDÉS, C. Reologia de las mesclas para helado de soya. Alimentaria, v. 36, n. 289, p. 87-88, apr., 1998.

21 PANORAMA BRASIL. Soja. Disponível em: <http://br.news.yahoo.com/030228/ 13/atpa.html>. Acesso em: 31 mar. 2003.

22 PAZ FRASSINO, M. T.; PEREA, J.; NÚÑEZ de VILLAVICENCIO, M.; HERNANÁNDEZ, R. Desarrollo de una bebida de soya-suero aromatizada com chocolate. Alimentaria, v. 36, n. 289, p. 83-86, apr., 1998.

23 PENNA, A. L. B.; SIVIERI, K.; OLIVEIRA, M. N. Relation between quality and 
rheological properties of latic beverages. Journal of Food Engeneering, v. 49 , p. $7-13,2001$.

24 PRUDÊNCIO, E.; FALCÃO, L. D.; BODIGNON LUIZ, M. T.; HAMAD, A. J. S.; BENEDET, H. D. Elaboração de uma bebida a partir de extrato de soja (Glycine max) adicionado de soro de queijo e antioxidantes. In: CONGRESSO BRASILEIRO DE CIÊNCIA E TECNOLOGIA DE ALIMENTOS, 18., 2002, Porto Alegre. Anais... Porto Alegre: UFRGS, 2002. 1 CD-ROM.

25 REDDY, P. V.; MITAL, B. K. Physical and chemical characteristics of soy milk. Journal of Food Science and Technology, v. 29, n. 3, p. 193-194, 1992.

26 RUSTOM, I. Y. S.; LÓPEZ-LEINA, M. M.; NAIR, B. M. UHT sterilized peanut beverages : kinetics of physicochemical changes during storage and shelf-life prediction modeling. Journal of Food Science, v. 61, n. 1, p. 198-203, 1996.

27 SAXENA, S.; SINGH, G. Suitability of new soybeans cultivars in the production of soy milk. Journal of Food Science and Technology, v. 34, n. 2, p. 150152, 1997.

28 SILVA, F. C. da; WANG, S. H.; FERNANDES, S. M.; ASCHERI, J. L. R.; CABRAL, L. C. Propiedades reologicas y sensoriales de bebidas reconstituidas a base de extracto hidrosoluble de arroz y soya. Alimentaria, v. 36, n. 289, p. 67-72, set., 1998.

29 STATISTICA for Windows: release 5.0 A. Tulsa: Statsoft Inc., 1995.

30 TRINDADE, C. S. F.; SILVA, E. C.; FREITAS, S.; COURI, S. Comportamiento reológico de los yogurts de soya homogeneizados y no homogeneizados. Alimentaria, v. 34, n. 279, p. 69-73, set., 1997.

31 WANG, B.; XIONG, Y. L.; WANG, C. Physicochemical and sensory characteristics of flavored soymilk during refrigeration storage. Journal of Food Quality, v. 24, p. 513-526, 2001.

32 YANES, M.; DURÁN, L.; COSTELL, E. Effect of hydrocolloid type and concentration on flow behaviour and sensory properties of milk beverages model systems. Food Hydrocolloids, v. 16, p. 605-611, 2002. 